\title{
Effects of the Antioxidant Sulforaphane on Hyperlocomotion and Prepulse Inhibition Deficits in Mice after Phencyclidine Administration
}

\author{
Yumi Shirai, Yuko Fujita, Kenji Hashimoto \\ Division of Clinical Neuroscience, Chiba University Center for Forensic Mental Health, Chiba, Japan
}

\begin{abstract}
Objective: Accumulating evidence suggests that oxidative stress plays a role in the pathophysiology of schizophrenia and that the potent antioxidants may be potential therapeutic drugs for schizophrenia. This study was undertaken to examine the effects of the potent antioxidant sulforaphane (SFN), found in cruciferous vegetables, on behavioral abnormalities (e.g., hyperlocomotion and prepulse inhibition [PPI] deficits) in mice after a single administration of the $N$-methyl-D-aspartate (NMDA)-receptor antagonist phencyclidine (PCP).

Methods: Effects of SFN (3, 10, and $30 \mathrm{mg} / \mathrm{kg}$, intraperitoneally [i.p.]) on hyperlocomotion and PPI deficits in the adult male ddY mice after administration of PCP (3.0 mg/kg, subcutaneously [s.c.]) were examined.

Results: Administration of SFN (30 mg/kg, intraperitoneally [i.p.]), but not low doses (3 and $10 \mathrm{mg} / \mathrm{kg}$, i.p.), significantly attenuated hyperlocomotion in mice after PCP administration (3.0 mg/kg, subcutaneously [S.C.]). Furthermore, administration of SFN (3, 10 , and $30 \mathrm{mg} / \mathrm{kg}$, i.p.) attenuated the PPI deficits in mice after PCP administration (3.0 mg/kg, s.c.) in a dose-dependent manner. Conclusion: These results suggest that SFN has antipsychotic activity in an animal model of schizophrenia. Therefore, it is likely that SFN may be a potential therapeutic drug for schizophrenia.
\end{abstract}

KEY WORDS: Schizophrenia; Phencyclidine; Prepulse inhibition; Sulforaphane; Antioxidants; Nrf2 activator.

\section{INTRODUCTION}

Multiple lines of evidence suggest that a dysfunction in glutamatergic neurotransmission via the $N$-methyl-D-aspartate (NMDA) receptor might be involved in the pathophysiology of schizophrenia. ${ }^{1-8)}$ NMDA receptor antagonists such as phencyclidine (PCP) and ketamine induce schizophrenia-like symptoms including positive symptoms, negative symptoms, and cognitive deficits in healthy subjects; ${ }^{1,9-12)}$ consequently, PCP has been used widely in animal models of schizophrenia. ${ }^{13-20)}$ Prepulse inhibition (PPI) of the acoustic startle response in the form of sensorimotor gating is defined as an inhibition of the startle response when a low-intensity stimulus, the prepulse, precedes the startle stimulus. Deficits in PPI have been reported in several psychiatric disorders including schizophrenia, suggesting that deficient PPI per se or ab-

\footnotetext{
Received: March 21, 2012 / Revised: April 21, 2012

Accepted: May 2, 2012

Address for correspondence: Kenji Hashimoto, PhD

Division of Clinical Neuroscience, Chiba University Center for Forensic Mental Health, 1-8-1 Inohana, Chiba 260-8670, Japan

Tel: +81-43-226-2517, Fax: +81-43-226-2561

E-mail: hashimoto@faculty.chiba-u.jp
}

normalities in neural circuits regulating PPI may cause some symptoms of schizophrenia. ${ }^{21-24)}$ Therefore, pharmacological models of PCP-induced PPI deficits are excellent predictors of antipsychotic activity. ${ }^{25-28)}$

Accumulating evidence suggests that oxidative stress plays a role in the pathophysiology of schizophrenia and that potent antioxidants would be potential therapeutic drugs for schizophrenia. ${ }^{29-38)}$ The potent antioxidant sulforaphane (SFN, 1-isothiocyanato-4-methylsulfinylbutane) (Fig. 1) is an organosulfur compound derived from a glucosinolate precursor found in cruciferous vegetables such as broccoli, Brussels sprouts, and cabbage. ${ }^{39-41)}$ SFN is also derived largely from its glucosinolate through the action of endogenous myrosinase during the isolation procedure and chewing.

Nuclear factor E2-related factor 2 (Nrf2) is a master regulator that induces a battery of cytoprotective genes, including antioxidative enzymes, antiinflammatory mediators, the proteasome, and several transcription factors in-<smiles>CS(=O)CCCCN=C=S</smiles>

Fig. 1. Chemical structure of sulforaphane (SFN). 
volved in mitochondrial biogenesis. ${ }^{41-43)}$ Following its nuclear translocation, Nrf2 binds the antioxidant response elements (AREs) in the promoter regions of its target genes. The protection afforded by SFN is thought to be mediated via activation of the Nrf2 pathway and subsequent upregulation of phase II detoxification enzymes and antioxidant proteins, through an enhancer sequence referred to as the electrophilic responsive elements or AREs. ${ }^{41-43)}$ We have reported that SFN prevents behavioral abnormalities and dopaminergic neurotoxicity in mice after administration of the psychostimulant methamphetamine, suggesting that SFN could be a potential therapeutic drug for neuropsychiatric diseases, including methamphetamine abuse. ${ }^{44)}$

Considering the potent antioxidant action of SFN, we hypothesized that SFN may possess antipsychotic activity in animal models of schizophrenia. Therefore, the present study was conducted to investigate whether SFN attenuates hyperlocomotion and PPI deficits in mice after PCP administration.

\section{METHODS}

\section{Animals}

Male Std:ddy mice (age, 6 weeks old; weight, 25-30 g) were purchased from SLC Japan (Hamamatsu, Shizuoka, Japan). The mice were housed in clear polycarbonate cages $(22.5 \times 33.8 \times 14.0 \mathrm{~cm})$ in groups of five or six per cage under a controlled 12/12-hour light-dark cycle (lights on from 7:00 $\mathrm{AM}$ to 7:00 $\mathrm{PM}$ ), with room temperature at $23 \pm 1^{\circ} \mathrm{C}$ and humidity of $55 \pm 5 \%$. The mice were given free access to water and food pellets. This experimental procedure was approved by the Animal Care and Use Committee of Chiba University.

\section{Drugs}

SFN was purchased from Toronto Research Chemicals, Inc. (North York, Ontario, Canada) and was dissolved in $10 \%$ corn oil (Wako Pure Chemical Co., Tokyo, Japan). PCP hydrochloride was synthesized in our laboratory, and the dose $(3.0 \mathrm{mg} / \mathrm{kg})$ of PCP was expressed as a hydrochloride salt. Other drugs were purchased from commercial sources.

\section{Effect of SFN on Hyperlocomotion after a Single Administration of PCP}

After habituation (30 minutes) in the cage, SFN or vehicle was injected into mice ( $\mathrm{n}=8$ /group). Thirty minutes after a single administration of SFN $(3.0,10$, or $30 \mathrm{mg} / \mathrm{kg}$, intraperitoneally [i.p.]) or vehicle $(10 \mathrm{ml} / \mathrm{kg}, 10 \%$ corn oil), PCP (3.0 mg/kg) or vehicle (physiological saline; 10 $\mathrm{ml} / \mathrm{kg}$ ) was administered subcutaneously (s.c.) to the mice. Locomotor activity was measured using an animal movement-analysis system (SCANET MV-40; Melquest, Toyama, Japan). The system consisted of a rectangular enclosure $(560 \times 560 \mathrm{~mm})$. The side walls (height, $60 \mathrm{~mm})$ of the enclosure were equipped with 144 pairs of photosensors located at 6-mm intervals at a height of $30 \mathrm{~mm}$ from the bottom edge. An animal was placed in the observation cage 30 minutes (habituation) before injection of vehicle or SFN. Vehicle or PCP was injected 30 minutes after injection of vehicle or SFN, and locomotor activity was measured for 120 minutes after injection. A pair of photosensors was scanned every 0.1 second to detect animal movements. The intersection of paired photosensors (10 mm apart) in the enclosure was counted as one unit of locomotor activity. Data collected for 180 minutes were used in this study. The sum of locomotion in mice for 120 minutes after PCP administration was used for data analysis.

\section{Effect of SFN on PPI Deficits after a Single PCP Injection}

The mice were tested for their acoustic startle reactivity in a startle chamber (SR-LAB; San Diego Instruments, San Diego, CA, USA) using standard methods described previously. ${ }^{45-48)}$ The test sessions began after an initial 10-minute acclimation period in the chamber. The mice were subjected to one of six trials: (1) pulse alone, as a $40-\mathrm{ms}$ broadband burst; the pulse (40-ms broadband burst) preceded by $100 \mathrm{~ms}$ with a $20-\mathrm{ms}$ prepulse that was (2) $4 \mathrm{~dB}$, (3) $8 \mathrm{~dB}$, (4) $12 \mathrm{~dB}$, or (5) $16 \mathrm{~dB}$ above background level ( $65 \mathrm{~dB}$ ); or (6) background only (no stimulus). The amount of PPI was expressed as the percentage decrease in the amplitude of the startle reactivity caused by presentation of the prepulse (\% PPI). SFN (3.0, 10, or $30 \mathrm{mg} / \mathrm{kg})$ or vehicle $(10 \%$ corn oil $)(10 \mathrm{ml} / \mathrm{kg})$ was administered i.p. 30 minutes (including the 10-minute acclimation period) before the machine began recording, and PCP $(3.0 \mathrm{mg} / \mathrm{kg})$ or saline $(10 \mathrm{ml} / \mathrm{kg})$ was administered s.c. 10 minutes (including the 10-minute acclimation period) before. The PPI test lasted 20 minutes in total.

\section{Statistical Analysis}

Data are presented as the mean \pm standard error of the mean. Hyperlocomotion data were analyzed by one-way analysis of variance (ANOVA), followed by a post hoc Bonferroni/Dunn test. The PPI data were analyzed by 


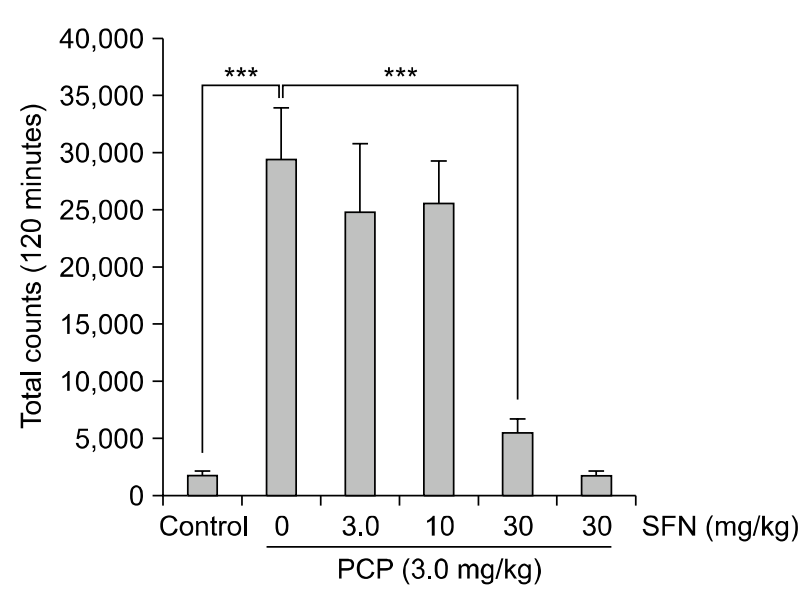

Fig. 2. Effect of sulforaphane (SFN) on phencyclidine (PCP)induced hyperlocomotion in mice. Thirty minutes after a single intraperitoneally administration of vehicle $(10 \mathrm{ml} / \mathrm{kg}$ ), or SFN (3.0, 10 or $30 \mathrm{mg} / \mathrm{kg}$ ), PCP (3 mg/kg) or vehicle (10 ml/kg) was administered subcutaneously into the mice. Behavior (locomotion) in the mice was evaluated for 2 hours after administration of PCP. Each value is the mean \pm standard error of the mean $(n=8$ per group). ${ }^{* * *} p<0.001$ as compared with the vehicle +PCP group.

multivariate analysis of variance (MANOVA). When appropriate, group means at individual $\mathrm{dB}$ levels were compared by one-way ANOVA, followed by a post hoc Bonferroni/Dunn test. A $p$-value $<0.05$ was considered significant.

\section{RESULTS}

A single administration of PCP $(3.0 \mathrm{mg} / \mathrm{kg}$, s.c. $)$ markedly increased locomotion in mice. The one-way ANOVA revealed significant differences among the six groups $(F$ $[5,42]=14.18, p<0.001]$. Pretreatment with SFN (30 $\mathrm{mg} / \mathrm{kg}$ ), but not low doses ( 3 and $10 \mathrm{mg} / \mathrm{kg}$ ), significantly $(p<0.001)$ attenuated PCP-induced hyperlocomotion in mice (Fig. 2). In contrast, administration of SFN (30 mg/kg) alone did not affect spontaneous locomotion in mice.

Fig. 2 shows the effects of SFN $(3.0,10$, or $30 \mathrm{mg} / \mathrm{kg})$ on PCP $(3.0 \mathrm{mg} / \mathrm{kg})$-induced PPI deficits in mice. The MANOVA analysis of all PPI data revealed a significant effect (Wilks lambda $=0.500 ; p<0.001$ ). Subsequent ANOVA analyses revealed significant differences $(p<$ $0.001)$ for all $\mathrm{dB}$ groups $(69,73,77$, and $81 \mathrm{~dB})$. A post hoc analysis indicated a significant $(p<0.001)$ difference in PPI deficits between the vehicle and vehicle + PCP (3.0 $\mathrm{mg} / \mathrm{kg}$ ) groups at all $\mathrm{dB}$ levels (Fig. 3). Pretreatment with SFN $(3.0,10$, or $30 \mathrm{mg} / \mathrm{kg})$ attenuated PCP-induced PPI deficits in a dose-dependent manner. A high SFN dose (30 $\mathrm{mg} / \mathrm{kg}$ ) significantly attenuated PCP-induced PPI deficits at 73 and $81 \mathrm{~dB}$ (Fig. 3). In contrast, PPI in mice after SFN

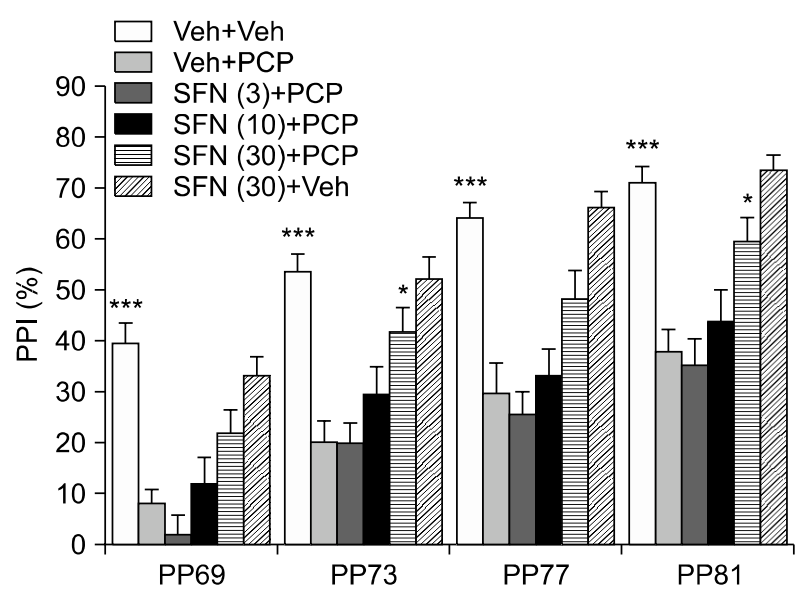

Fig. 3. Effect of sulforaphane (SFN) on phencyclidine (PCP)induced prepulse inhibition deficits in mice. Thirty minutes after a single intraperitoneally administration of vehicle $(10 \mathrm{ml} / \mathrm{kg})$, or SFN (3.0, 10 or $30 \mathrm{mg} / \mathrm{kg}$ ), PCP (3 mg/kg) or vehicle $(10 \mathrm{ml} / \mathrm{kg}$ ) was administered subcutaneously to the mice. Each value is the mean \pm standard error of the mean ( $n=17-21$ per group). PPI, prepulse inhibition. ${ }^{*} p<0.05,{ }^{* *} p<0.01$ as compared with the vehicle + PCP treated group.

administration $(30 \mathrm{mg} / \mathrm{kg})$ alone was similar to that in control mice (Fig. 3).

\section{DISCUSSION}

We found that SFN attenuated hyperlocomotion and PPI deficits in mice after PCP administration. This is the first report to demonstrate that SFN is effective in a PCP model of schizophrenia. We have reported that SFN attenuates acute hyperlocomotion in mice after a single administration of methamphetamine and that SFN blocks the development of behavioral sensitization after repeated administration of methamphetamine. ${ }^{44)}$ Additionally, we have reported that SFN protects against dopaminergic neurotoxicity in the striatum after repeated administration of methamphetamine. ${ }^{44)}$ Taken together, these findings suggest that SFN could be a potential therapeutic drug for schizophrenia.

SFN is widely reported to induce Nrf2-dependent gene expression, although its molecular targets have not been fully characterized. ${ }^{42,43)}$ It remains unclear whether activation of the Nrf-2-electrophile-responsive element/ARE pathway accounts for the ability of SFN to diminish the acute behavioral effects (e.g., hyperlocomotion and PPI deficits) induced by PCP in mice. SFN increases Nrf2 protein levels in the mouse striatum, and SFN protected against methyl-4-phenyl-1,2,3,6-tetrahydropyridine-induced death of nigral dopaminergic neurons in a cell-cul- 
ture model of Parkinson's disease. ${ }^{49)}$ We have also reported that SFN could protect against dopaminergic neurotoxicity in the mouse striatum after repeated methamphetamine administration. ${ }^{44)}$ Taken together, these results suggest the likelihood that SFN protects against dopaminergic neurotoxicity in the mouse striatum by increasing Nrf2 expression, although this needs to be confirmed. Further studies on the other mechanisms of SFN to ameliorate PCP-associated acute neurochemical and behavioral effects will also be necessary.

Adjunctive medication for antipsychotic treatment is one approach used to improve several symptoms (e.g., positive symptoms, negative symptoms, cognitive impairment) of schizophrenia. A number of potential therapeutic drugs for schizophrenia have been developed, ${ }^{50-53)}$ but no reports have shown the efficacy of SFN in patients with schizophrenia, although dietary SFN-rich sprouts reduce colonization and attenuate gastritis in Helicobacter pylo$r i$-infected humans. ${ }^{54)}$ Additionally, a phase II study of SFN (200 $\mu \mathrm{mol}$ [35 mg] daily) in patients with recurrent prostate cancer is now in progress (NCT01228084). Therefore, it is of great interest to study the effects of SFN on symptoms of schizophrenia. A randomized, placebo-controlled study of SFN (or dietary SFN-rich sprouts) adjunctive therapy will be necessary to confirm the clinical efficacy of this effect in patients with schizophrenia.

In conclusion, the present results suggest that SFN has potential antipsychotic activity in an animal model of schizophrenia. Therefore, SFN could potentially be used to treat schizophrenia, as it is a naturally occurring compound found in cruciferous vegetables.

\section{acknowledgments}

This study is supported partly by a grant for Intramural Research Grant (22-2: to K.H.) for Neurological and Psychiatric Disorders of NCNP, Japan.

\section{REFERENCES}

1. Javitt DC, Zukin SR. Recent advances in the phencyclidine model of schizophrenia. Am J Psychiatry 1991;148:13011308.

2. Olney JW, Farber NB. Glutamate receptor dysfunction and schizophrenia. Arch Gen Psychiatry 1995;52:998-1007.

3. Coyle JT. The glutamatergic dysfunction hypothesis for schizophrenia. Harv Rev Psychiatry 1996;3:241-253.

4. Krystal JH, D’Souza DC, Petrakis IL, Belger A, Berman RM, Charney DS, et al. NMDA agonists and antagonists as probes of glutamatergic dysfunction and pharmacotherapies in neuropsychiatric disorders. Harv Rev Psychiatry 1999;7: 125-143.

5. Hashimoto K, Fukushima T, Shimizu E, Komatsu N, Watanabe H, Shinoda N, et al. Decreased serum levels of $D$-serine in patients with schizophrenia: evidence in support of the N-methyl-D-aspartate receptor hypofunction hypothesis of schizophrenia. Arch Gen Psychiatry 2003;60:572-576.

6. Gaisler-Salomon I, Schobel SA, Small SA, Rayport S. How high-resolution basal-state functional imaging can guide the development of new pharmacotherapies for schizophrenia. Schizophr Bull 2009;35:1037-1044.

7. Hashimoto K, Shimizu E, Iyo M. Dysfunction of glia-neuron communication in pathophysiology of schizophrenia. Curr Psychiatry Rev 2005;1:151-163.

8. Hashimoto K. The NMDA receptor hypofunction hypothesis for schizophrenia and glycine modulatory sites on the NMDA receptors as potential therapeutic drugs. Clin Psychopharmacol Neurosci 2006;4:3-10.

9. Krystal JH, Karper LP, Seibyl JP, Freeman GK, Delaney R, Bremner JD, et al. Subanesthetic effects of the noncompetitive NMDA antagonist, ketamine, in humans. Psychotomimetic, perceptual, cognitive, and neuroendocrine responses. Arch Gen Psychiatry 1994;51:199-214.

10. Anand A, Charney DS, Oren DA, Berman RM, Hu XS, Cappiello A, et al. Attenuation of the neuropsychiatric effects of ketamine with lamotrigine: support for hyperglutamatergic effects of $\mathrm{N}$-methyl-D-aspartate receptor antagonists. Arch Gen Psychiatry 2000;57:270-276.

11. Krystal JH, Anand A, Moghaddam B. Effects of NMDA receptor antagonists: implications for the pathophysiology of schizophrenia. Arch Gen Psychiatry 2002;59:663-664.

12. Krystal JH, Perry EB Jr, Gueorguieva R, Belger A, Madonick SH, Abi-Dargham A, et al. Comparative and interactive human psychopharmacologic effects of ketamine and amphetamine: implications for glutamatergic and dopaminergic model psychoses and cognitive function. Arch Gen Psychiatry 2005;62:985-994.

13. Jentsch JD, Roth RH. The neuropsychopharmacology of phencyclidine: from NMDA receptor hypofunction to the dopamine hypothesis of schizophrenia. Neuropsychopharmacology 1999;20:201-225.

14. Hashimoto K, Fujita Y, Shimizu E, Iyo M. Phencyclidineinduced cognitive deficits in mice are improved by subsequent subchronic administration of clozapine, but not haloperidol. Eur J Pharmacol 2005;519:114-117.

15. Hashimoto K, Fujita Y, Ishima T, Hagiwara H, Iyo M. Phencyclidine-induced cognitive deficits in mice are improved by subsequent subchronic administration of tropisetron: role of alpha7 nicotinic receptors. Eur J Pharmacol 2006;553: 191-195.

16. Hashimoto K, Fujita Y, Iyo M. Phencyclidine-induced cognitive deficits in mice are improved by subsequent subchronic administration of fluvoxamine: role of sigma-1 receptors. Neuropsychopharmacology 2007;32:514-521.

17. Hashimoto K, Ishima T, Fujita Y, Matsuo M, Kobashi T, Takahagi M, et al. Phencyclidine-induced cognitive deficits in mice are improved by subsequent subchronic administration of the novel selective alpha7 nicotinic receptor agonist SSR180711. Biol Psychiatry 2008;63:92-97.

18. Hashimoto K, Fujita $\mathrm{Y}$, Ishima T, Chaki S, Iyo M. Phencyclidine-induced cognitive deficits in mice are improved by subsequent subchronic administration of the glycine transporter-1 inhibitor NFPS and D-serine. Eur Neuropsychopharmacol 2008;18:414-421.

19. Hagiwara H, Fujita Y, Ishima T, Kunitachi S, Shirayama Y, Iyo $\mathrm{M}$, et al. Phencyclidine-induced cognitive deficits in mice are improved by subsequent subchronic administration of the antipsychotic drug perospirone: role of serotonin 5-HT1A receptors. Eur Neuropsychopharmacol 2008;18: $448-454$ 
20. Tanibuchi Y, Fujita Y, Kohno M, Ishima T, Takatsu Y, Iyo $\mathrm{M}$, et al. Effects of quetiapine on phencyclidine-induced cognitive deficits in mice: a possible role of alpha1-adrenoceptors. Eur Neuropsychopharmacol 2009;19:861-867.

21. Braff DL, Geyer MA. Sensorimotor gating and schizophrenia. Human and animal model studies. Arch Gen Psychiatry 1990;47:181-188.

22. Swerdlow NR, Braff DL, Taaid N, Geyer MA. Assessing the validity of an animal model of deficient sensorimotor gating in schizophrenic patients. Arch Gen Psychiatry 1994;51:139154.

23. Perry W, Geyer MA, Braff DL. Sensorimotor gating and thought disturbance measured in close temporal proximity in schizophrenic patients. Arch Gen Psychiatry 1999;56:277281.

24. Geyer MA, Krebs-Thomson K, Braff DL, Swerdlow NR. Pharmacological studies of prepulse inhibition models of sensorimotor gating deficits in schizophrenia: a decade in review. Psychopharmacology (Berl) 2001;156:117-154.

25. Bakshi VP, Swerdlow NR, Geyer MA. Clozapine antagonizes phencyclidine-induced deficits in sensorimotor gating of the startle response. J Pharmacol Exp Ther 1994;271: 787-794.

26. Javitt DC, Lindsley RW. Effects of phencyclidine on prepulse inhibition of acoustic startle response in the macaque. Psychopharmacology (Berl) 2001;156:165-168.

27. Yee BK, Chang DL, Feldon J. The Effects of dizocilpine and phencyclidine on prepulse inhibition of the acoustic startle reflex and on prepulse-elicited reactivity in C57BL6 mice. Neuropsychopharmacology 2004;29:1865-1877.

28. Egerton A, Reid L, McGregor S, Cochran SM, Morris BJ, Pratt JA. Subchronic and chronic PCP treatment produces temporally distinct deficits in attentional set shifting and prepulse inhibition in rats. Psychopharmacology (Berl) 2008; 198:37-49.

29. Mahadik SP, Mukherjee S. Free radical pathology and antioxidant defense in schizophrenia: a review. Schizophr Res 1996;19:1-17.

30. Matsuzawa D, Obata T, Shirayama Y, Nonaka H, Kanazawa Y, Yoshitome E, et al. Negative correlation between brain glutathione level and negative symptoms in schizophrenia: a 3T 1H-MRS study. PLoS One 2008;3:e1944.

31. Hashimoto K. Regarding "N-acetyl cysteine as a glutathione precursor for schizophrenia--a double-blind, randomized, placebo-controlled trial". Biol Psychiatry 2008;64:e1.

32. Do KQ, Conus P, Cuenod M. Redox dysregulation and oxidative stress in schizophrenia: nutrigenetics as a challenge in psychiatric disease prevention. World Rev Nutr Diet 2010;101:131-153.

33. Yao JK, Keshavan MS. Antioxidants, redox signaling, and pathophysiology in schizophrenia: an integrative view. Antioxid Redox Signal 2011;15:2011-2035.

34. Chowdari KV, Bamne MN, Nimgaonkar VL. Genetic association studies of antioxidant pathway genes and schizophrenia. Antioxid Redox Signal 2011;15:2037-2045.

35. Reddy R, Reddy R. Antioxidant therapeutics for schizophrenia. Antioxid Redox Signal 2011;15:2047-2055.

36. Matsuzawa D, Hashimoto K. Magnetic resonance spectroscopy study of the antioxidant defense system in schizophrenia. Antioxid Redox Signal 2011;15:2057-2065.

37. Martins-de-Souza D, Harris LW, Guest PC, Bahn S. The role of energy metabolism dysfunction and oxidative stress in schizophrenia revealed by proteomics. Antioxid Redox Signal 2011;15:2067-2079.

38. Bitanihirwe BK, Woo TU. Oxidative stress in schizophrenia an integrated approach. Neurosci Biobehav Rev 2011;35: 878-893.

39. Zhang Y, Li J, Tang L. Cancer-preventive isothiocyanates: dichotomous modulators of oxidative stress. Free Radic Biol Med 2005;38:70-77.

40. Juge N, Mithen RF, Traka M. Molecular basis for chemoprevention by sulforaphane: a comprehensive review. Cell Mol Life Sci 2007;64:1105-1127.

41. Yanaka A. Sulforaphane enhances protection and repair of gastric mucosa against oxidative stress in vitro, and demonstrates anti-inflammatory effects on Helicobacter pyloriinfected gastric mucosae in mice and human subjects. Curr Pharm Des 2011;17:1532-1540.

42. Cheung KL, Kong AN. Molecular targets of dietary phenethyl isothiocyanate and sulforaphane for cancer chemoprevention. AAPS J 2010;12:87-97.

43. Kwak MK, Kensler TW. Targeting NRF2 signaling for cancer chemoprevention. Toxicol Appl Pharmacol 2010;244: 66-76.

44. Chen $\mathrm{H}, \mathrm{Wu} \mathrm{J}$, Zhang J, Fujita $\mathrm{Y}$, Ishima T, Iyo $\mathrm{M}$, et al. Protective effects of the antioxidant sulforaphane on behavioral changes and neurotoxicity in mice after the administration of methamphetamine. Psychopharmacology (Berl) 2012;222:37-45.

45. Zhang L, Shirayama Y, Iyo M, Hashimoto K. Minocycline attenuates hyperlocomotion and prepulse inhibition deficits in mice after administration of the NMDA receptor antagonist dizocilpine. Neuropsychopharmacology 2007;32:20042010.

46. Hashimoto K, Fujita Y, Horio M, Kunitachi S, Iyo M, Ferraris D, et al. Co-administration of a D-amino acid oxidase inhibitor potentiates the efficacy of D-serine in attenuating prepulse inhibition deficits after administration of dizocilpine. Biol Psychiatry 2009;65:1103-1106.

47. Horio M, Fujita Y, Ishima T, Iyo M, Ferraris D, Tsukamoto $\mathrm{T}$, et al. Effects of D-amino acid oxidase inhibitor on the extracellular D-alanine levels and the efficacy of D-alanine on dizocilpine-induced prepulse inhibition deficits in mice. Open Clin Chem J 2009;2:16-21.

48. Takatsu Y, Fujita Y, Tsukamoto T, Slusher BS, Hashimoto $\mathrm{K}$. Orally active glutamate carboxypeptidase II inhibitor 2-MPPA attenuates dizocilpine-induced prepulse inhibition deficits in mice. Brain Res 2011;1371:82-86.

49. Jazwa A, Rojo AI, Innamorato NG, Hesse M, Fernández-Ruiz J, Cuadrado A. Pharmacological targeting of the transcription factor Nrf2 at the basal ganglia provides disease modifying therapy for experimental parkinsonism. Antioxid Redox Signal 2011;14:2347-2360.

50. Hashimoto K. Glycine transporter-1: a new potential therapeutic target for schizophrenia. Curr Pharm Des 2011;17: 112-120.

51. Ishikawa M, Hashimoto K. a 7 nicotinic acetylcholine receptor as a potential therapeutic target for schizophrenia. Curr Pharm Des 2011;17:121-129.

52. Niitsu T, Iyo M, Hashimoto K. Sigma-1 receptor agonists as therapeutic drugs for cognitive impairment in neuropsychiatric diseases. Curr Pharm Des 2012;18:875-883.

53. Yoshida $\mathrm{T}$, Iyo M, Hashimoto $\mathrm{K}$. Recent advances in the potential therapeutic drugs for cognitive deficits in schizophrenia. Curr Psychiatry Rev 2012;8:140-150.

54. Yanaka A, Fahey JW, Fukumoto A, Nakayama M, Inoue S, Zhang S, et al. Dietary sulforaphane-rich broccoli sprouts reduce colonization and attenuate gastritis in Helicobacter pylori-infected mice and humans. Cancer Prev Res (Phila) 2009;2:353-360. 